\title{
EL TURISMO GASTRONÓMICO, RUTAS TURÍSTICAS Y PRODUCTOS LOCALES: EL CASO DEL VINO Y EL QUESO EN CATALUÑA
}

\author{
G. Molleví Bortoló \\ Doctora en Geografía \\ Universitat de Barcelona \\ gmollevi@yahoo.es \\ F. Fusté Forné \\ Doctor en Turismo, Derecho y Empresa \\ Universitat de Girona \\ researchexperiencetourism@gmail.com
}

\begin{abstract}
Resumen: El turismo gastronómico es una tipología turística cuya práctica se extiende a lo largo de todo el año, y que se da en contextos geográficos de cualquier índole. A su vez, las rutas turísticas, tanto naturales como culturales, representan un producto turístico que contribuye también a la desestacionalización de la actividad turística, con un gran potencial para el desarrollo regional. El presente artículo analiza de forma descriptiva el caso del turismo gastronómico en Cataluña a través de la oferta de los productos locales mediante las rutas turísticas. Para ello, se estudian cuatro casos de rutas turísticas y gastronómicas en torno a dos productos en particular, el vino y el queso. Las rutas analizadas reflejan una parte del gran mosaico de posibilidades turísticas de Cataluña vinculadas a la potenciación y visibilidad del turismo rural y su impacto económico, y se valora desde un punto de vista teórico cómo han permitido la defensa y valorización del paisaje agrario y de su patrimonio cultural en general y gastronómico en particular.
\end{abstract}

Palabras clave: Cataluña, enoturismo, productos locales, rutas turísticas, turismo gastronómico. 


\begin{abstract}
Culinary tourism is a type of tourism whose practice occurs throughout the whole year, and in any geographical context. Tourist routes, both natural and cultural, represent a product that also contributes to reduce the seasonality of tourism, with wider potential for regional development. This article describes the case of food tourism in Catalonia regarding the offer of local products through tourist routes. Consequently, four cases of tourist and gastronomic routes around two particular products (wine, cheese) are studied. The highlighted routes reflect part of the great mosaic of rural tourism opportunities in Catalonia. These are linked to the empowerment and visibility of rurality, and to its economic impact. From a theoretical perspective, it usefully serves to the recovery and valorization of agricultural landscapes and cultural heritage, particularly the culinary.
\end{abstract}

Keywords: Catalonia, wine tourism, local products, tourist routes, culinary tourism.

\title{
1. Introducción
}

El auge del turismo gastronómico y enológico en España es un fenómeno reciente, que ha ido aumentando su importancia exponencialmente a lo largo de los últimos años. Tanto es así, que no es hasta hace poco más de una década, en el año 2003, cuando Hall y Sharples proclamaron la que se considera la definición más aceptada del concepto de turismo gastronómico y que analizamos más adelante. Desde entonces han sido muchas las aportaciones teóricas en torno a este fenómeno $y$, desde el inicio de la segunda década del siglo XXI, las investigaciones tanto conceptuales como empíricas se han convertido en contenido habitual de las principales revistas científicas de turismo, en el ámbito nacional y en el internacional. Consecuentemente, el turismo gastronómico ha pasado de estar incluido dentro del turismo cultural, del turismo rural y del turismo urbano, a tener una entidad propia. En este contexto, no se puede obviar que el desarrollo y consolidación del enoturismo sucede con anterioridad al turismo gastronómico tal y como se concibe en la actualidad, y que éste aprovecha muchas de las características y aprendizajes del enoturismo para darse a conocer. Por ejemplo, en el caso europeo, ha estado vinculado más al entorno agrario y rural, además de al desarrollo endógeno de diferentes realidades regionales; en cambio, en otros entornos como el africano y el asiático se ha avanzado hacia un producto gastronómico ligado más al exotismo y a aspectos socioculturales.

Particularmente, el turismo gastronómico y enoturístico de Cataluña se beneficia de otros tipos de turismo: culturales y naturales, agrarios y paisajísticos, patrimoniales e históricos; al respecto, incluyendo el redescubrimiento de la artesanía y las raíces de las sociedades rurales anteriores a las comunidades urbanas actuales. Esto se puede ver am- 
pliamente estudiado en la literatura francesa (por ejemplo en Bèssiere, 1998; 2006), pero también para el caso español y catalán (por ejemplo, Cànoves, Herrera y Cuesta, 2005; Cànoves, Herrera y Villarino, 2005; Díaz y Llurdés, 2013). Una forma de explorar los entornos rurales es hacerlo a través de la creación de rutas fruto tanto de iniciativas públicas como privadas, como también mixtas. Estas se refieren por ejemplo a rutas de indicaciones geográficas protegidas, o también a rutas vinculadas a diferentes aspectos temáticos, relacionadas con las sociedades que crearon y evolucionaron sus culturas gastronómicas.

Esta investigación tiene como objetivo analizar la oferta de turismo gastronómico en Cataluña a través de la puesta en valor de los productos locales, estructurados en este caso en rutas turísticas. Para ello, se describen los casos de dos productos en particular como son el vino y el queso, utilizando como casos de estudio Enoturisme Penedès, la Ruta del Vino de Lleida-Costers del Segre, la Ruta Artesana y la Ruta del Cister. La Figura 1 de la página siguiente muestra la localización en un mapa de la Comunidad Autónoma de Cataluña de las cuatro rutas turísticas gastronómicas que se describen de forma individual en el presente trabajo para extraer posteriormente una serie de conclusiones generales.

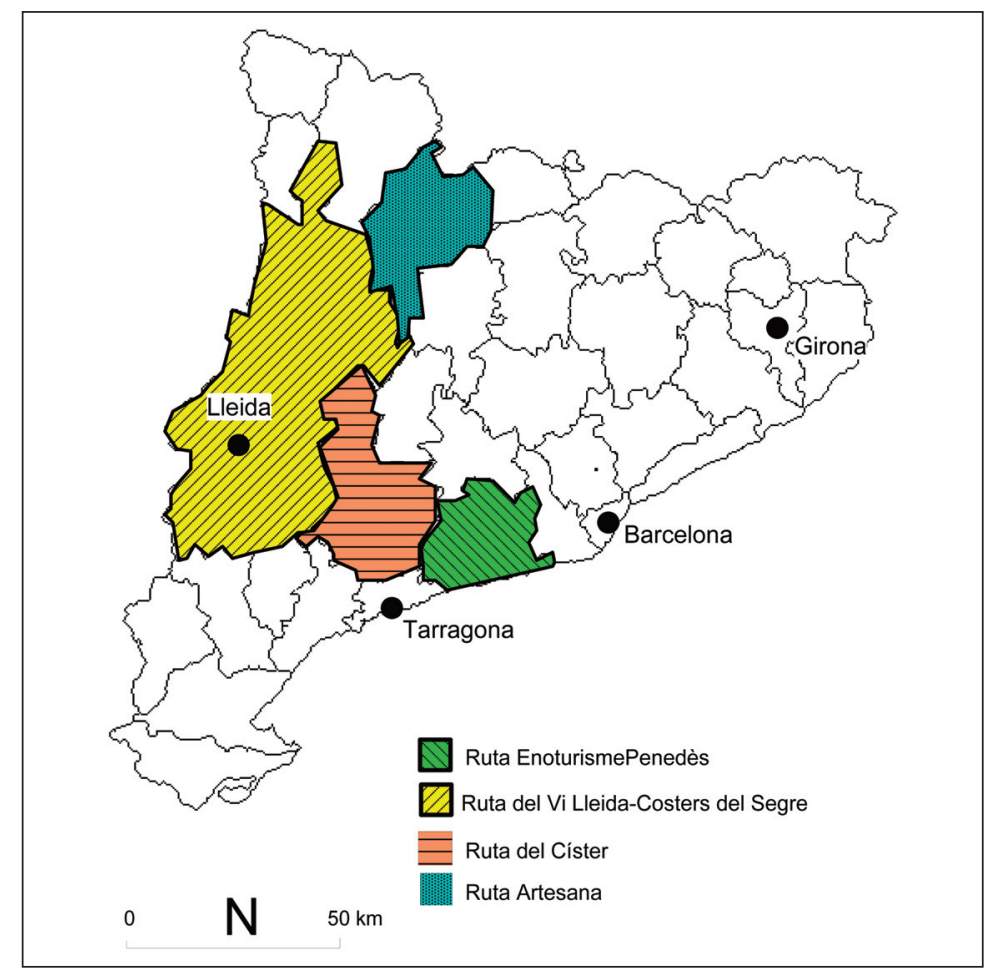

Figura 1. Mapa de las rutas turísticas gastronómicas analizadas.

Fuente: Elaboración propia a partir del ámbito geográfico de cada una de las rutas. 


\section{Una aproximación al turismo gastronómico}

Cataluña es una de las zonas en las que más se ha estado trabajado e impulsando el turismo gastronómico y enológico, con un gran hincapié por parte de la administración pública. Esto se puede constatar gracias a la gran cantidad de actividades, productos y rutas turísticas que se ofrecen en la actualidad desde la propia Agencia Catalana de Turismo (2015) y que tiene un punto álgido en la distinción este año 2016 de Cataluña como Región Europea de la Gastronomía. Esto lleva implícitos un conjunto de actos y celebraciones que ponen en valor los productos gastronómicos del territorio y su capacidad de atracción en relación a la motivación turística.

Tanto la gastronomía como la enología se podrían englobar conjuntamente en el estudio del turismo gastronómico, pues, en muchos casos, cuando se habla de turismo gastronómico se hace referencia tanto al conocimiento y degustación de los productos como de las bebidas. Sin embargo, no son pocas las veces que el turismo del vino se presenta por separado y de forma individualizada y es el factor sobre el que gira una ruta turística específicamente: es entonces cuando se habla de enoturismo, un concepto que también ha sido ampliamente estudiado en la literatura (por ejemplo, LópezGuzmán, García, y Rodríguez, 2013).

El enoturismo ha sido la primera agroindustria procedente de un recurso agrario -la vid y la uva- que ha conseguido una cierta autonomía dentro del turismo gastronómico (Getz and Brown, 2006; Hall, Sharples, Cambourne y Macionis, 2009), aunque otros productos están siguiendo sus pasos de forma activa: el óleoturismo (Guerra, Moreno y López, 2014; Millán, Morales y Agudo, 2010), el cual gira alrededor del aceite de oliva y de la visita a olivos centenarios o incluso milenarios con el valor añadido que llevan implícito; o, más recientemente, el fruiturismo, la visita al paisaje de árboles de fruta dulce en flor, tales como los melocotoneros y ciruelos, como sucede en Aitona (Visa, 2015) y que lleva mucho tiempo desarrollándose en el Valle extremeño del Jerte con los cerezos en flor. Se está haciendo evidente, pues, la diversidad de actividades turísticas que están surgiendo desde el mundo rural, a partir de paisajes y productos agrarios y artesanos que desde la base de un recurso paisajístico, histórico, se están convirtiendo en productos turísticos. Este fenómeno tiene efectos en cualquier producción del sector primario y proporciona una importante baza para el desarrollo local a partir de la transformación de los recursos procedentes del espacio agrario.

El turismo gastronómico engloba actividades como recorrer el lugar donde se cultiva el producto agroalimentario y conocer el proceso que da lugar a un determinado alimento (sea el queso, la mermelada, la miel, el chocolate, la sal), la visita a museos sobre este producto y la degustación, bien en catas, bien en restaurantes, bien en determinados eventos. En el caso concreto del turismo enológico, se visitan y se pueden realizar paseos por los viñedos, tanto a pie, como a caballo o en bicicleta, aprender el proceso de elabora- 
ción del vino y del cava, degustar vinos, visitar museos o incluso disfrutar de masajes a base de cremas de vino o de barro hecho a partir de las pieles de las uvas. Esta variedad de oportunidades que se generan alrededor del turismo gastronómico encaja con la definición de Hall y Sharples (2003) cuando se refieren al turismo gastronómico como el desplazamiento motivacional a regiones gastronómicas, con el objetivo de visitar productores primarios y secundarios, eventos como festivales, ferias culinarias o mercados, así como cualquier otra manifestación relacionada con los productos de la tierra.

En el caso de los productos locales y usando el ejemplo del vino al tratarse de los pioneros, lo que se hacía hasta hace poco era que las bodegas hicieran su propia programación para recibir a los visitantes. Pero para aumentar la visibilidad, la productividad y la venta, diferentes realidades empresariales vitivinícolas se juntaron con el objetivo de crear rutas del vino. Posteriormente se fueron creando otras rutas vinculadas con la gastronomía y la elaboración de productos agrarios, lo que en cierto modo vendría a ser la artesanía.

Actualmente aún las rutas enológicas siguen siendo las más representativas, pero están ganando fuerza otras rutas gastronómicas, a la vez que éstas son capaces de englobar un conjunto de actividades, recursos y productos que permiten un enriquecimiento cultural y geográfico a los visitantes. Hay que tener en cuenta, además, que en el contexto de la mayoría de los destinos -tanto maduros que sería el caso de Francia y Estados Unidos de América, como emergentes en el caso de China con sus terrazas de cultivo de arroz (Lignon, 2009) - incluida Cataluña, este tipo de turismo está muy vinculado tanto con el turismo rural como con los espacios de interior (Cànoves, 2004).

Esto es debido al carácter fuertemente agrario que tienen la mayor parte de las comarcas de interior catalanas, muchas de ellas de montaña debido a las características geográficas del territorio, y a factores históricos, geográficos y sociales. Cataluña fue, y sigue siendo en parte, una tierra de agricultores, los cuales han necesitado trabajar el campo para producir su alimento y generar unos extras para comercializarlo. Este saber hacer de la gente del campo no se ha perdido y, ahora, poco a poco, se está recuperando y valorizando gracias al turismo gastronómico (Fusté, 2015a). Los visitantes y turistas, en muchas ocasiones ciudadanos urbanos, visitan estas tierras para conocer y aprender cómo se conseguían y cómo se consiguen hoy en día los productos que posteriormente se saborean en la mesa. Por lo tanto, se ha pasado de que la oferta generase una demanda turística, a que ahora la demanda de adquisición de cultura dé lugar a la creación de una oferta en particular: rutas con las que los visitantes aprendan cómo se hace vino, cómo se hace miel, cómo se hace aceite o cómo se pastorea un rebaño de ovejas. Asimismo, se ha introducido un aspecto substancial: el afán de conocer y el sentido de identidad de un producto con el territorio (natural y social) que lo genera. Todo ello tiene antecedentes en la actividad realizada por el gobierno francés para impulsar el turismo enológico, gastronómico y artesanal en todo su territorio, pero en especial en las zonas rurales y de interior, con muy poca densidad de población (Lignon, 
2009). Posteriormente, el gobierno español ha estado desarrollando este tipo de turismo para impulsar regiones rurales y de interior con el propósito de desarrollarlas económicamente al ofrecer nuevas actividades económicas (Molleví, 2015). Sería ejemplo de ello, la red de restaurantes ubicados en los Paradores Nacionales, lugares en los cuales se ofrece una gastronomía local, basada en los productos de la tierra y de temporada.

En este sentido, dentro de la literatura vinculada al desarrollo e implementación de las rutas turísticas y gastronómicas, Briedenhann y Wickens (2003) definen las rutas turísticas como la puesta en valor de una amalgama de actividades y atracciones que incentivan la cooperación entre diferentes sectores, como se decía anteriormente, y en consecuencia pueden servir como base sólida para con el desarrollo económico regional de un determinado lugar. De acuerdo con López-Guzmán y Margarida (2011), una ruta gastronómica consiste en definir un itinerario en un área geográfica concreta donde se indiquen los diferentes lugares donde los viajeros puedan apreciar su gastronomía. Por lo tanto, y según los mismos autores, "las rutas deben de servir para desarrollar económica y socialmente la zona geográfica, para lo cual se busca que el viajero encuentre una experiencia basada en el conocimiento, en la apreciación y degustación del vino, y que todo ello sirva para valorizar el turismo de dicha área geográfica” (López-Guzmán y Margarida, 2011, p. 920).

En la misma dirección, ACEVIN (2015) destaca al respecto de las Rutas del Vino: "el turismo enológico se ha consolidado como un importante complemento a la oferta turística española, que representa una interesante alternativa para planificar un viaje de corta estancia y distancia y que tras unos años de crecimiento más moderado el ritmo de aumento de enoturistas se recupera y aumenta". El enoturismo en Cataluña y España es un complemento turístico importante a destinos turísticos consolidados con el turismo de masas de sol y playa, que permite crear un desarrollo económico en áreas del interior del país, y en muchas ocasiones con vinos reconocidos a escala internacional.

De rutas gastronómicas hay tanto aquellas especializadas, o temáticas, como otras articuladas alrededor de uno o varios recursos agrarios y/o gastronómicos. A veces es la gastronomía y la cata de vino el origen de la creación de la ruta, a veces éstos son solo un complemento que sirven de excusa para mostrar la arquitectura de las bodegas donde se elaboraban vino y aceite o de los monasterios a partir de los cuales se generó la expansión de la vitivinicultura en Cataluña. Muchas de las rutas gastronómicas y enológicas que hay actualmente en Cataluña están vinculadas a la existencia de Denominaciones de Origen Protegidas (DOP), especialmente las vitivinícolas, o Indicaciones Geográficas Protegidas (IGP) para productos de la tierra de gran calidad. Por ejemplo, en Cataluña hay 12 DOP (INCAVI, 2015), que son: Alella, Catalunya, Cava (estatal), Conca de Barberà, Costers del Segre, Empordà, Penedés, Pla de Bages, Montsant, Tarragona, Terra Alta y la DOP Calificada Priorat, que es la que tiene una mayor calificación y de la cual solo hay otra en todo el Estado Español que es la DOP Calificada La Rioja. Además, el territorio catalán aglutina alrededor de 20 Indicaciones Geográfi- 
cas (MAGRAMA, 2015), como por ejemplo: Aceite de Oliva del Empordà, Avellana de Reus, Arroz del Delta del Ebro, Calçot de Valls, Queso del Alt Urgell y de la Cerdanya, Aceite de Oliva de Siurana, Ternera de los Pirineos, Pera de Lleida, entre otras.

Así pues, la creación e institución de una Denominación de Origen o de una Indicación Geográfica Protegida es una manera de identificar y poner en valor un producto agrario, de regularlo y de poner unas premisas de calidad que sirven tanto para el productor como para el consumidor; también, de darle un valor añadido beneficioso para la promoción turística. Como dice INCAVI (el órgano gestor de las Denominaciones de Origen vitivinícolas catalanas), "la Denominación de Origen garantiza el origen geográfico y también la calidad de un vino, que el vino está elaborado a partir de unas determinadas variedades y con prácticas vitícolas, enológicas y de envejecimiento previamente establecidas". En la misma dirección, MAGRAMA (2015) indica que "las Denominaciones de Origen Protegidas (DOP) e Indicaciones Geográficas Protegidas (IGP) constituyen el sistema utilizado en nuestro país para el reconocimiento de una calidad diferenciada, consecuencia de características propias y diferenciales, debidas al medio geográfico en el que se producen las materias primas, se elaboran los productos, y a la influencia del factor humano que participa en las mismas".

Tal y como se recoge en Hernández (2011), el fenómeno de la proliferación de las rutas turísticas se debe tanto a la creciente preocupación por la protección medioambiental y el desarrollo sostenible, como en relación a la motivación para explorar las culturas desde un punto de vista auténtico. En consecuencia, "en el terreno de la práctica turística se manifiesta en un deseo cada vez más generalizado por conocer espacios naturales, sociedades singulares y bienes patrimoniales; y de otro, la expansión social del patrimonio que implica el surgimiento de nuevas categorías patrimoniales como las de paisaje e itinerario cultural" (Hernàndez, 2011, p. 226). Esto es de aplicación en este artículo para las rutas gastronómicas.

\section{Metodología}

La metodología utilizada es el estudio de caso. Si bien la literatura en torno al estudio de caso como metodología de investigación es amplia, la aproximación metodológica del presente estudio se basa en Yin (1994). Con el objetivo de analizar el turismo gastronómico a partir de la vertebración de los productos locales mediante las rutas turísticas, el presente es un estudio cualitativo que desde un punto de vista descriptivo y conceptual analiza el caso de Enoturisme Penedès, la Ruta del Vino de LleidaCosters del Segre, la ruta Artesana, y la Ruta del Cister. Los dos primeros ejemplos tratan el caso del vino, el enoturismo, ampliamente consolidado en el contexto de Cataluña; así, se desarrollan dos rutas de particular interés en dos entornos geográficos distintos, uno en la zona del Penedés, y el segundo en un territorio de interior, las 
comarcas de Lleida. El interés por ésta relación entre el vino y el turismo en el caso de Cataluña es también especialmente relevante en la literatura existente (Medina y Tresserras, 2008; Molleví, 2008, 2014). El tercer caso trata la ruta Artesana, que se desarrolla alrededor del queso, que es un producto estrechamente ligado al territorio de los Pirineos, y a la historia y evolución de su sociedad rural. También el caso del queso ha sido recientemente tema de interés científico en el contexto particular de los Pirineos catalanes (Fusté, 2014, 2015b, 2016). Finalmente, la Ruta del Cister se utiliza también como ejemplo dado que se trata de un caso de integración de diferentes atractivos turísticos y culturales, donde se puede observar la incorporación del recurso gastronómico en una ruta concebida no sólo por su componente gastronómico. Asimismo, algunas de estas rutas turísticas y gastronómicas ya tienen cierto recorrido, por lo que disponen de datos estadísticos que permiten valorar su impacto en el territorio, en el sector turístico y en los aspectos sociales que se verán plasmados en las conclusiones.

\section{Casos de estudio: rutas gastronómicas en Cataluña}

En este apartado se describen 4 ejemplos de rutas gastronómicas existentes en Cataluña, escogidos por su experiencia o por su implantación reciente y novedosa. En el primer caso tendríamos EnoturismePenedès y Ruta del Cister y en el segundo caso la Ruta Artesana y la Ruta Lleida-Costers del Segre. EnoturismePenedès y la Ruta LleidaCosters del Segre son rutas turísticas enológicas, en las que el hilo conductor gira en torno a la cultura del vino; la Ruta Artesana es una ruta turística gastronómica en relación a la transformación de productos de la tierra en productos agrarios, particularmente el queso; y la Ruta del Cister es una ruta turística cultural donde la gastronomía es uno de los aspectos importantes junto a la arquitectura, la religión y la naturaleza.

\subsection{EnoturismePENEDÈS}

EnoturismePENEDÈS es la ruta del vino por las comarcas del Penedès que se encuentran entre las ciudades de Barcelona y Tarragona formando un arco interior. Es la primera ruta del vino presente en Cataluña y la más importante de España como muestra el Gráfico 1, pues es la que recibe mayor número de visitantes y turistas (ACEVIN, 2015). Forma parte de la red enoturística "Rutas del Vino de España", creada a principios de siglo por ACEVIN (Asociación Española de Ciudades del Vino) con el objetivo de dar a conocer uno de los bienes patrimoniales más importantes que tiene España: el vino.

La demanda de turismo enológico en España ha ido en aumento de forma sostenida desde 2008 (un millón de visitantes) cuando empezaron los primeros informes. Como se puede apreciar en el Gráfico 2 de la página anterior, del millón de visitantes del 2008 se pasó a los dos millones de 2014. 


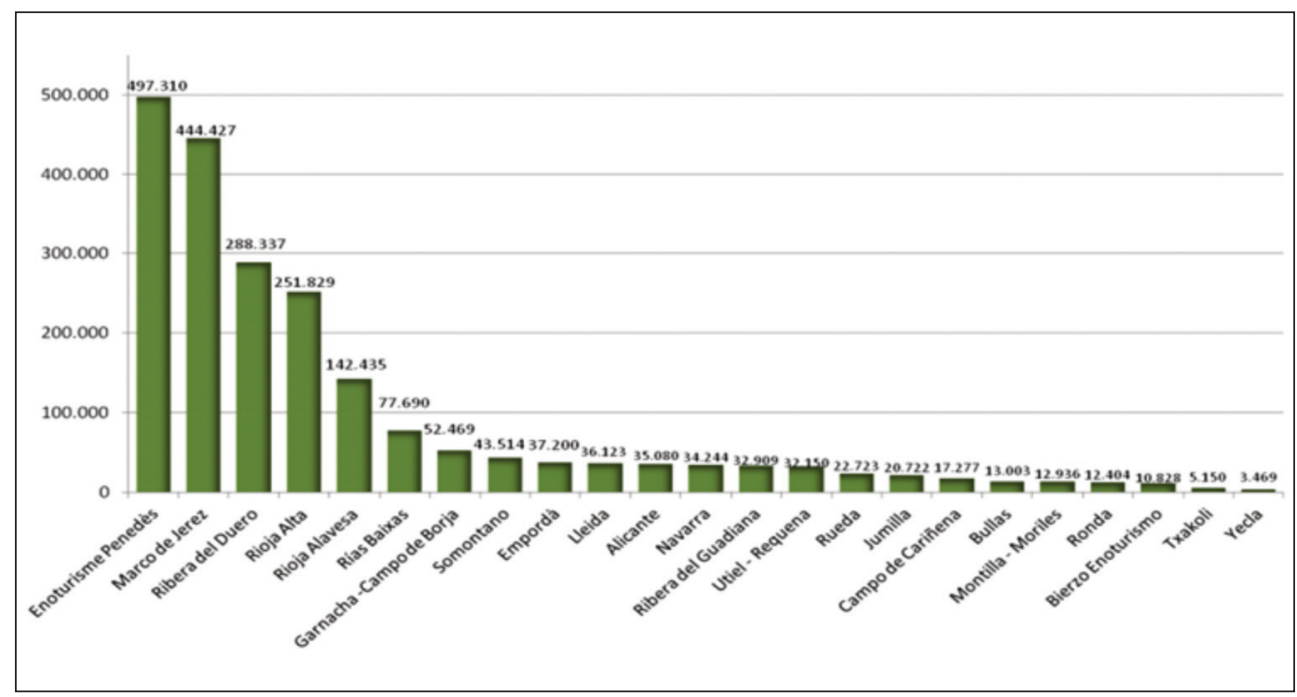

Gráfico 1. Número de visitantes a bodegas y museos del vino por Rutas ACEVIN, 2014.

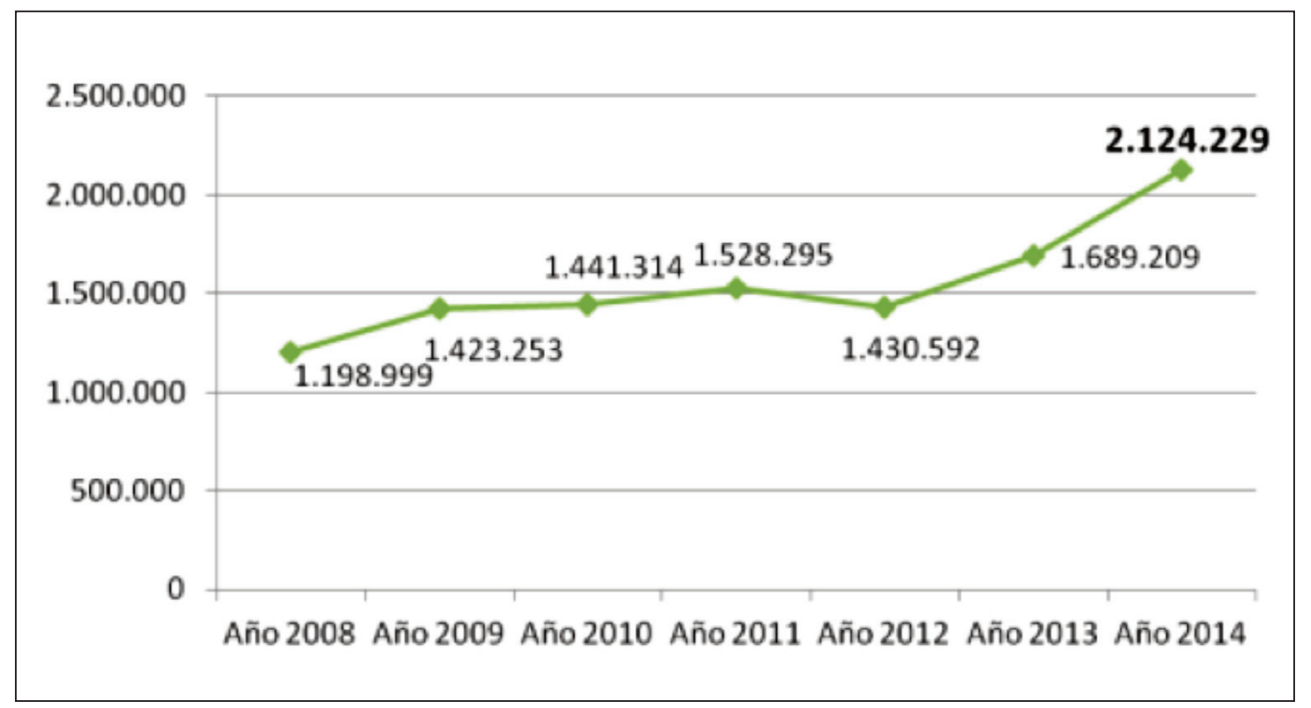

Gráfico 2. Evolución de los visitantes a las Rutas del Vino de España, 2008-2014.

Fuente: ACEVIN, 2015. 
En un principio, EnoturismePenedès recibía el nombre de Ruta del cava y del vino del Alt Penedès, en la que se establecían 5 circuitos indicando las direcciones y los horarios de visitas de las bodegas presentes en la comarca del Alt Penedès, en especial de su capital Sant Sadurní d'Anoia, la cual es a la vez capital del Cava (Molleví, 2015). Sin embargo, hace unos años, se hizo necesaria su ampliación, para poder incluir bodegas ubicadas en otras zonas de la DOP Penedès, como aquellas de las comarcas del Baix Penedès y Garraf. Sin embargo, se aprovechó la ocasión para implantar otro cambio: ya no se trataría sólo de presentar un listado de bodegas y cavas, sino que además se señalarían otros bienes de interés turístico como edificios de valor patrimonial, rutas por los espacios naturales protegidos y celebraciones festivas emblemáticas (Molleví, 2016).

En la ruta enológica EnoturismePENEDÈS participan tres importantes bodegas productoras de cava y vino, como son Cavas Codorniu, Cavas Freixenet y Bodegas Torres. Estas tres bodegas son de hecho las pioneras en el enoturismo catalán, pues se aprovecharon de su experiencia norteamericana para impulsar un tipo de turismo inexistente en España (Molleví, 2008): recepción de visitantes y turistas, y cata de vinos. Además, añadieron algo muy americano: las tiendas de recuerdos donde se pueden adquirir todo tipo de objetos para recordar la visita (camisetas, llaveros, decantadores de vinos, juegos de copas, puzles para los pequeños de la familia y peluches). Hay que tener en cuenta que estas empresas familiares se instalaron en los Estados Unidos para poder exportar sus vinos y cavas producidos en Cataluña a finales del siglo XX. Al mismo tiempo, la ruta permite visitar el Museo de las Culturas del Vino de Cataluña, popularmente conocido como Vinseum, creado en 1945 en Vilafranca del Penedès. Es el centro museístico más importante y antiguo de España relacionado con el sector vitivinícola (Vinseum, 2015). El Museo, gestionado por una fundación pública, está ubicado en un edificio de gran valor patrimonial, el antiguo Palacio Real de la Corona de Aragón y Cataluña, construido durante los siglos XII y XIII. Actualmente puede ser visitado con todo su esplendor tras una gran reforma y rehabilitación que ha durado más de una década.

La ruta engloba dos grandes ciudades del vino: Sant Sadurní d'Anoia, capital del Cava, y Vilafranca del Penedès, capital del vino del Penedès. A lo largo de todo el año se realizan en ambas ciudades fiestas y celebraciones vinculadas con el sector vitivinícola, como la Fiesta de la Filoxera, con la gastronomía como unos de los ingredientes principales, como la promoción del chocolate, o con la cultura, como conciertos de jazz (EnoturismePENEDÈS, 2016). La ruta se beneficia de la presencia de dos estaciones de tren de servicio regular con la ciudad de Barcelona. De esta manera, es una alternativa a aquellos visitantes y turistas que quieren conocer Barcelona, pero pueden disponer de un día para desplazarse a la región metropolitana vitivinícola y conocer la cultura del vino. Y es que la misma administración pública, tanto la provincial como la autonómica, organiza visitas de medio día o día entero por la región vitivinícola del Penedès (Figura 2), incluyendo una visita a la Montaña de Montserrat o Sitges.

Las ventajas de EnoturismePENEDÈS son su situación geográfica, que dispone de buenas comunicaciones, que ha realizado una muy buena promoción turística y que se ha estado haciendo un muy buen trabajo de gestión turística, con una innovación continua. 


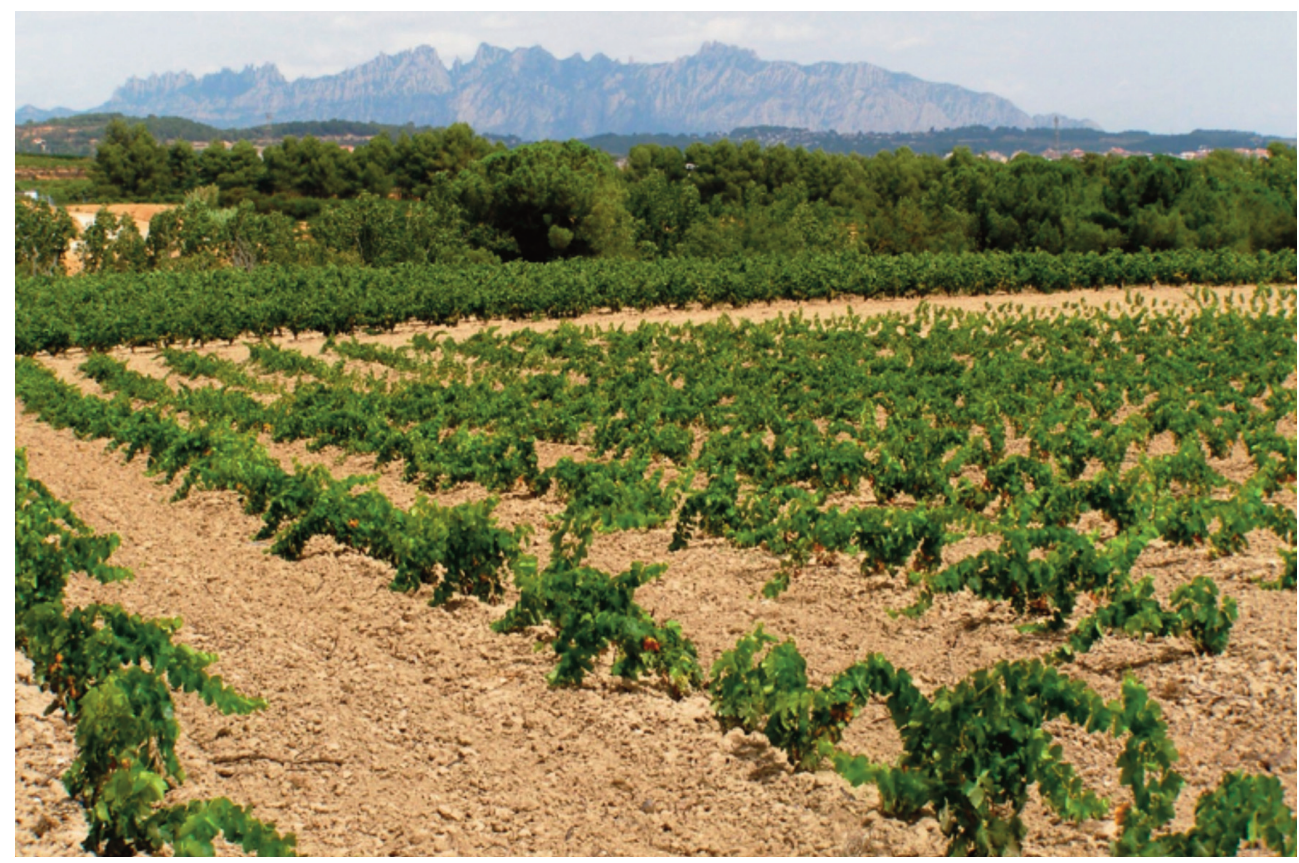

Figura 2. Región paisajística del Penedès con la sierra de Montserrat al fondo.

Fuente: Gemma Molleví, 2014.

\subsection{La ruta del vino de Lleida-Costers del Segre}

La Ruta del Vino de Lleida-Costers del Segre fue creada en 2010 con el objetivo de promover el enoturismo en la provincia de Lleida. Esta ruta fue impulsada a partir de la existencia de bodegas importantes desde hace décadas en la zona -aunque desconocidas- y del empuje reciente del sector vinícola de la región; además aprovecha otros recursos turísticos existentes y ha permitido la creación de otros nuevos. La ruta aprovecha la existencia de la DOP Costers del Segre, la cual fue creada en el año 1988. Esta DOP se divide en siete subzonas que son: Raimat, Segrià, Pallars, Garrigues, Valls del Riu Corb, Artesa de Segre y Urgell. Es una DOP que abarca el territorio comprendido desde la depresión de Lleida en el sur hasta las montañas del Pirineo al norte; por lo tanto, sus vinos serán tan diferentes como la diversa orografía y paisaje geográfico del que proceden.

Curiosamente, la Ruta del Vino de Lleida-Costers del Segre no utiliza las subzonas de la DOP, sino que las engloba como un todo para crear una única ruta. Así es como utiliza el reclamo de la cultura del vino (visitas a bodegas y viñedos) para dar a conocer otros bienes patrimoniales, como monumentos y edificios civiles y religiosos (Molleví, 2014) y otros paisajes agrarios formados por campos de olivos y árboles de fruta 
dulce (melocotoneros, perales y manzanos). En 2014, según datos de ACEVIN (2015) y tal como aparece en el Gráfico 2, esta ruta tuvo 36.123 visitantes, lo que representa el $1,7 \%$ del total de las rutas del vino españolas (en décimo lugar). Pero hay que tener en cuenta que es una ruta de nueva creación, que se encuentra en el interior, que aún no se ha dado mucho a conocer y que no tiene una comunicación tan buena como con las ciudades catalanas que reciben más turistas (Barcelona, Tarragona o Girona). También se debe valorar que mientras EnoturismePENEDÈS se beneficia de un turismo internacional gracias a su proximidad con un gran foco receptor de turistas como es Barcelona, estos mismos turistas desconocen la Ruta del Vino Lleida-Costers del Segre por falta de promoción y accesibilidad.

Los elementos que forman la Ruta del Vino de Lleida-Costers del Segre son: 20 bodegas, 19 restaurantes, 13 alojamientos, 3 enotecas, 3 oficinas de turismo (las de Lleida, Tremp y Verdú) y 4 ofertas turísticas y culturales (Consorci del Turó de la Seu Vella, Cicerone Turisme Cultural, Como Pomona Consultoria Gastronòmica y Espai Macià). Entre los bienes patrimoniales de los que consta destacan Els Vilars de Arbeca -con restos del antiguo poblado íbero-, la Seu Vella de Lleida, los Monasterios de Vallbona de les Monges (Figura 3) -uno de los tres pilares básicos de la Ruta del Cister que se comentará a continuación- y de Las Avellanas y el castillo de Verdú (Molleví, 2014).

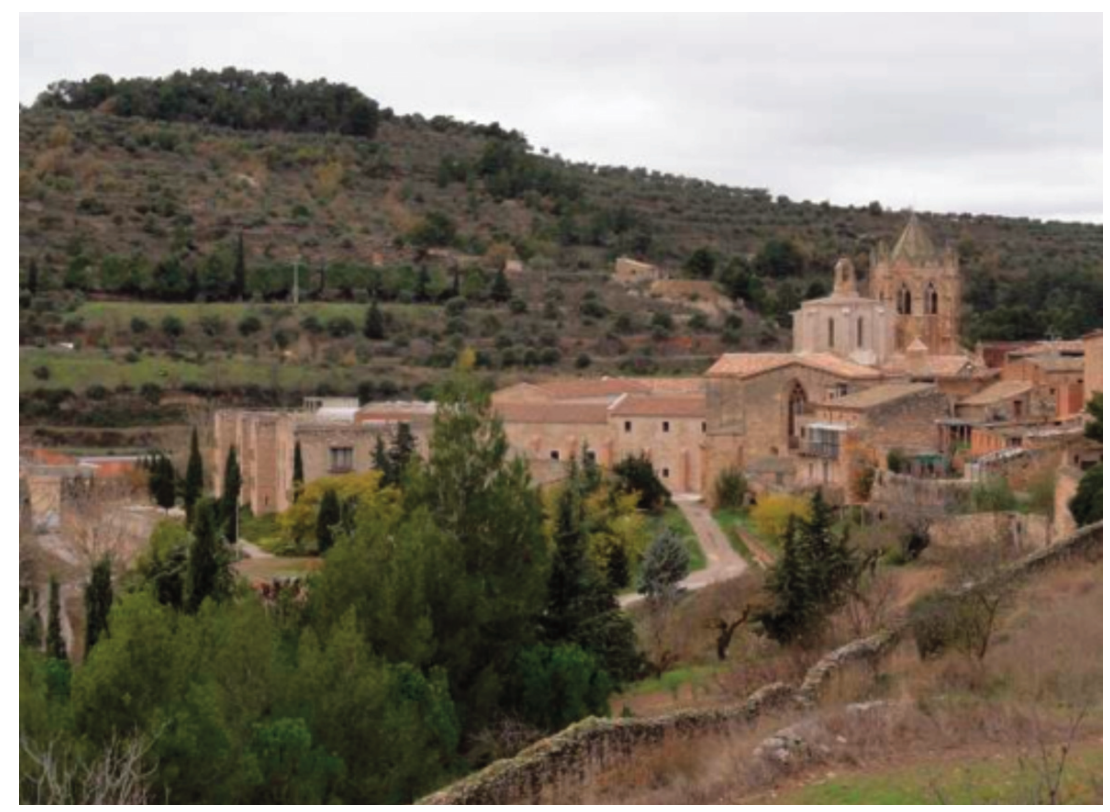

Figura 3. Viñas en Vallbona de les Monges, en la DOP Costers del Segre. Fuente: Gemma Molleví, 2014. 
Asimismo, se puede realizar senderismo por los parajes naturales de Les Garrigues, de La Terreta y del Montsec (no se debe confundir el espacio leridano del Montsec con la sierra del Montsec, pues la primera hace frontera natural con la Comunidad Autónoma de Aragón, mientras que la segunda es un paraje natural de gran interés a nivel europeo ubicado en Tarragona).

\subsection{La ruta artesana}

La Ruta Artesana (Fet a Mà en catalán y que significa hecho a mano en su traducción literal, es decir artesanal) permite conocer este tipo de productos de la comarca del Alt Urgell, con el objetivo de seguir su proceso de elaboración, su degustación en los obradores y su consumo en los restaurantes de la comarca (Turisme de la Seu d'Urgell, 2015). La ruta, pues, permite que los visitantes puedan experimentar en primera persona la elaboración de los productos artesanales, la autenticidad de los cuales se encuentra fuertemente arraigada al contexto cultural y natural del territorio, en este caso, el Alt Urgell. La Figura 4 muestra como se reflejan estos factores en la promoción turística.
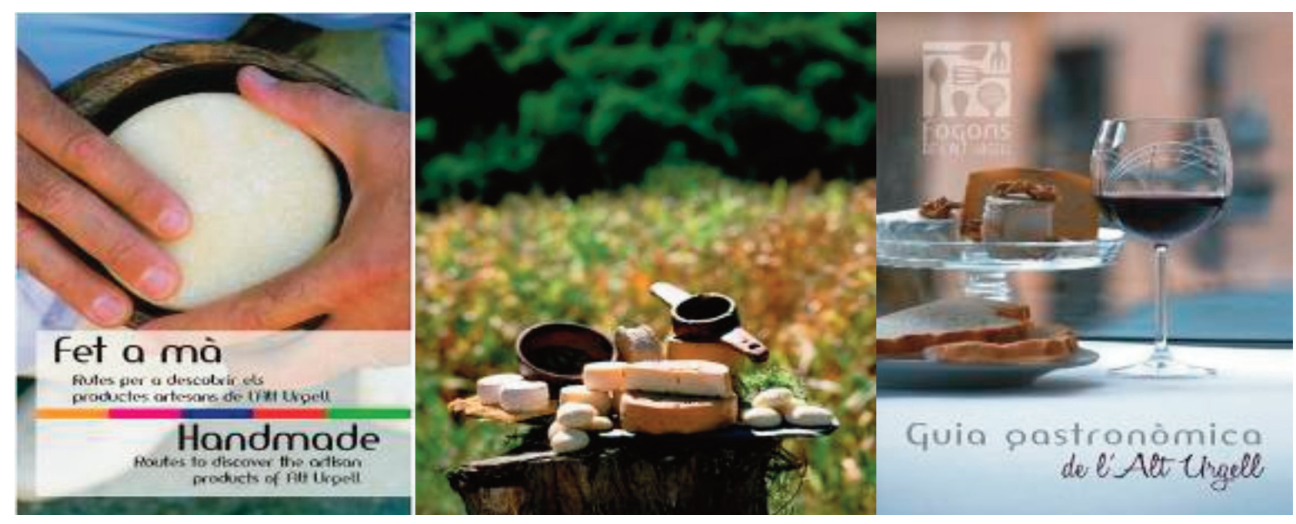

Figura 4. Imágenes de la promoción de la Ruta Artesana (equivalente a Fet a Mà).

Fuente: Turisme de la Seu d'Urgell (2015).

El producto más destacado de este itinerario turístico es el queso, con variedades según la procedencia (de vaca, de oveja y de cabra) y con la característica de encontrarnos ante el único queso con Denominación de Origen Protegida de Cataluña, Urgètia. De la producción ganadera y derivada del producto lácteo se distingue una mantequilla también Denominación de Origen Protegida, la mantequilla del Cadí. Cabe decir que se trata de los únicos productos derivados de la leche, tanto el queso como la mantequilla, que tienen esta etiqueta de calidad en toda Cataluña. Este hecho es muy im- 
portante en el contexto de los Pirineos, ya que la elaboración de quesos se remonta a hace más de mil años, y ha tenido en los Pirineos una de sus tradiciones más importantes, impulsada a partir de principios del siglo XX con la creación de las grandes cooperativas -Lleteries de la Seu y la Cooperativa del Cadí, que en 2015 celebraba su centenario-. Lógicamente, la sociedad actual es depositaria de una cultura, culinaria especialmente, que se mantiene viva y se refleja a través de la elaboración artesanal de quesos, manifiesta en productos como las rutas.

De los cinco itinerarios que forman la ruta, hay cuatro que tienen el queso como elemento principal. Se trata de los itinerarios Baridà, Tuixent Serrat Gros, Castell-llebre y Mas d'Eroles La Reula. Todos estos itinerarios recorren varias queserías artesanales de la comarca donde se elaboran y se comercializan una gran variedad de productos, como tipo de quesos pero también otros derivados lácteos como mantequillas y yogures. También se debe remarcar que todos los itinerarios se complementan con visitas a los principales recursos naturales -Parque Natural del Cadí Moixeró- y culturales -patrimonio románico- así como la posibilidad de asistir a diferentes eventos y celebraciones según la época del año en el cual nos encontremos.

El quinto itinerario se denomina La Seu d'Urgell Anserall, en el cual se visitan los principales recursos presentes en el territorio que va desde la población de la Seu d'Urgell hasta Anserall y donde buena parte de los restaurantes locales -que aprovechan esta ruta como una muy buena plataforma de promoción-. Estos restaurantes utilizan los productos locales en sus elaboraciones, lo cual ayuda también al desarrollo local y a un impacto del turismo en el territorio a través del uso de los productos $\mathrm{km} 0$. La utilización de productos locales por parte del sector turístico, en especial de los restauradores, es uno de los elementos clave para el desarrollo regional, ya que se impulsa un ciclo económico donde los pequeños artesanos, y empresarios, se benefician directamente del consumo tanto de visitantes como de turistas.

Lógicamente además de los productores artesanos de queso también se pueden visitar, a través de los itinerarios, otros artesanos como elaboradores de embutidos, de mermeladas o de setas. Los distintos recorridos de la Ruta Artesana abarcan buena parte de la comarca del Alt Urgell, lo cual es también un indicador del alcance regional de esta ruta. En la estructuración de la oferta turística es importante conseguir un impacto lo más amplio posible, y más aún en contextos rurales, de interior y de montaña donde los productos turísticos no tienen una demanda tan fuerte como en otros entornos. Esto se consigue no sólo a través del patrimonio gastronómico sino también gracias al conjunto de recursos culturales y naturales explotados, que además ayudan a la promoción y dinamización de otros sectores, como el mencionado de la restauración. 


\subsection{La ruta del Cister}

Los Monasterios de Vallbona de les Monges, Poblet y Santes Creus son los tres elementos alrededor de los cuales gira y se estructura la Ruta del Cister. Creada en 1989, ha dado lugar a una ruta turística que pretende dar a conocer el valor patrimonial de tres comarcas catalanas: Urgell, Conca de Barberà y Alt Camp, respectivamente. Los tres monasterios nos permiten adentrarnos en el paisaje, la gastronomía, la cultura y naturaleza de estos territorios (Oliver et al, 2008).

A finales del siglo XI, unos monjes benedictinos fundaron el monasterio del Cister en Borgoña (Francia), siguiendo con austeridad la regla de San Bernardo y creando la Orden del Cister. Los monjes se ubicaban en tierras despobladas que convertían en verdaderas explotaciones agrícolas donde aplicaban innovadoras técnicas agrarias (VV.AA., 2008).

A mediados del siglo XII, como instrumento de repoblación de las nuevas tierras conquistadas por la Corona de Aragón a los árabes, se favoreció la llegada de monjes del Cister. El objetivo era que los monjes construyeran un monasterio alrededor del cual se instalarían nuevos agricultores que trabajarían sus tierras, crearían poblaciones con mercados y actividades artesanales que permitirían la dinamización del territorio.

El Monasterio de Poblet (Figura 5) es el mayor de los tres monasterios de la ruta y dispone de una activa comunidad monástica masculina. Fue fundado en el siglo XII por Ramón Berenguer IV, conde de Barcelona; posteriormente, Pedro III el Ceremonioso (1336-1387) hizo del monasterio panteón real de la Corona de Aragón y Cataluña, y así encontramos su sepulcro y el de sus descendientes, como Jaime I el conquistador, Fernando de Antequera y Alfonso V el Magnánimo. Este panteón real es lo más sorprendente e interesante de la iglesia, aunque hay otros elementos igual de importantes, como el retablo y la sacristía (Oliver et al, 2008; VV.AA., 2008). El Monasterio de Poblet sufrió la destrucción y el abandono durante el siglo XIX, con las desamortizaciones. Posteriormente, en el siglo XX, se comenzó una tarea de reconocimiento y rehabilitación del conjunto monástico que permitió su mejora para que pudiera ser visitado en sus mejores condiciones en la actualidad. En 1991, fue declarado Patrimonio de la Humanidad por la UNESCO.

El Monasterio de Santes Creus es uno de los ejemplos monásticos mejor conservados en la actualidad. Fundado en 1168, protegido por la nobleza y la realeza, fue centro espiritual, de adquisición de conocimientos y ayudó a la colonización del territorio al permitir el asentamiento de familias campesinas que buscaban su supervivencia bajo su resguardo. Actualmente, es el único de los tres en los que no hay vida monástica y se ha convertido en un centro de interpretación que permite dar a conocer un periodo histórico de Cataluña: el de la Edad Media. Permite a los visitantes conocer cómo vivían los monjes en aquella época, cuáles eran sus tareas principales, cómo adquirieron sus conocimientos y cómo los dieron a conocer a la población. 


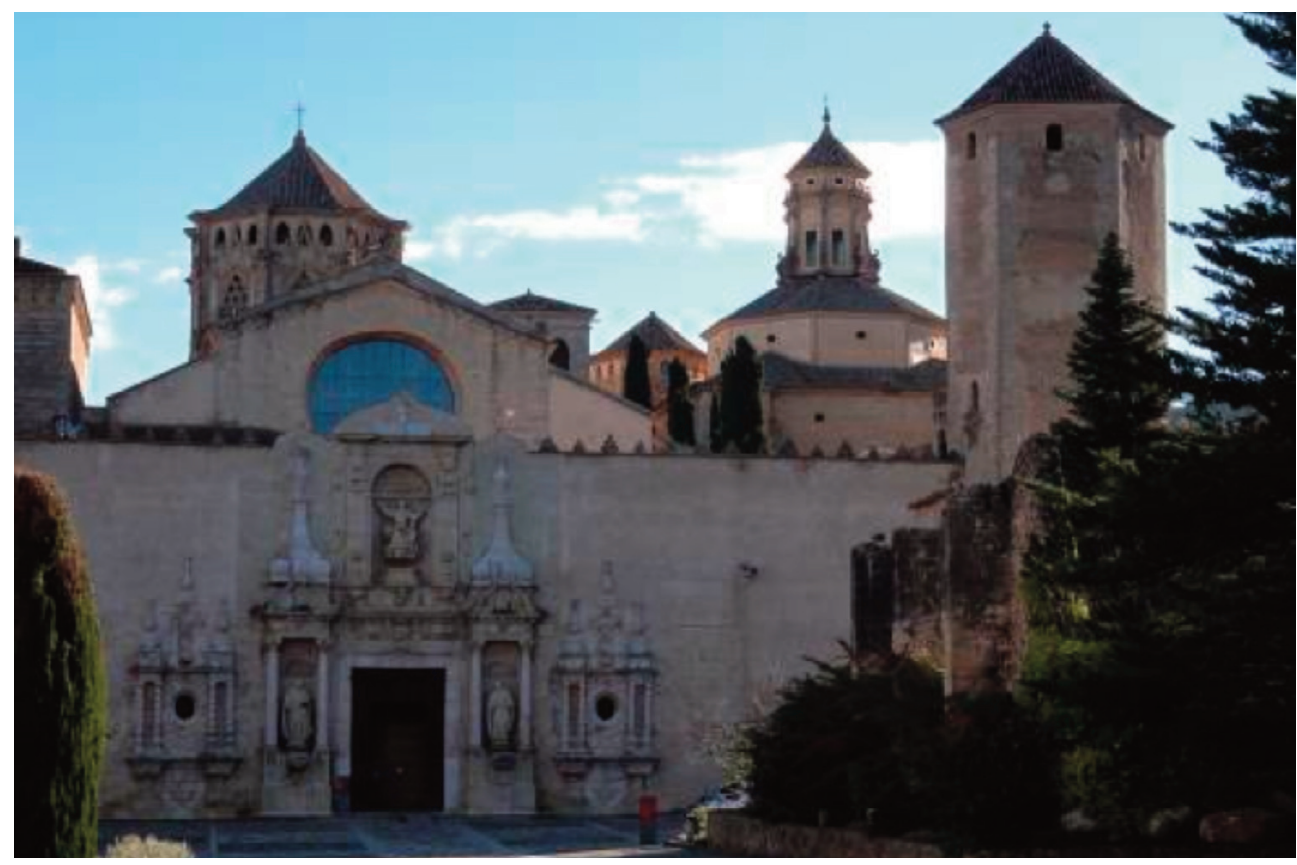

Figura 5. Fachada del Monasterio de Poblet.

Fuente: Gemma Molleví, 2014.

El Monasterio de Vallbona de les Monges, el monasterio femenino de la Ruta, ha conservado ininterrumpidamente la comunidad monástica durante más de 850 años, desde su construcción en el siglo XII. Muchas herederas de la nobleza catalana asistieron al convento para recibir una educación apropiada para la época (VV.AA., 2008). Su claustro es único en toda Europa, pues hay representados diferentes estilos artísticos.

La Ruta del Cister incluye otros lugares de interés, como las localidades de Les Borges Blanques, Montblanc o Valls. En primer lugar, en Les Borges Blanques se encuentra el Parque Temático del Aceite (Figura 6), donde acogidos de entrada por la presencia de una serie de olivos, podemos conocer cómo ha sido la evolución del cultivo del olivo y la elaboración, producción, transporte y comercialización del aceite, además de conocer los usos que tenían las aceitunas y el aceite -medicinales, lumínicas, religiosas-.

En segundo lugar, la localidad amurallada de Montblanc, donde se cree que tuvieron lugar los acontecimientos que originaron la Leyenda de San Jordi (patrón de Cataluña) durante la Edad Media. Y finalmente, el pueblo de Valls, centro turístico impulsado por la Fiesta del Calçot -plato gastronómico local- y uno de los centros neurálgicos de los Castellers, declarados Patrimonio Inmaterial de la Humanidad por la UNESCO en 2010. 


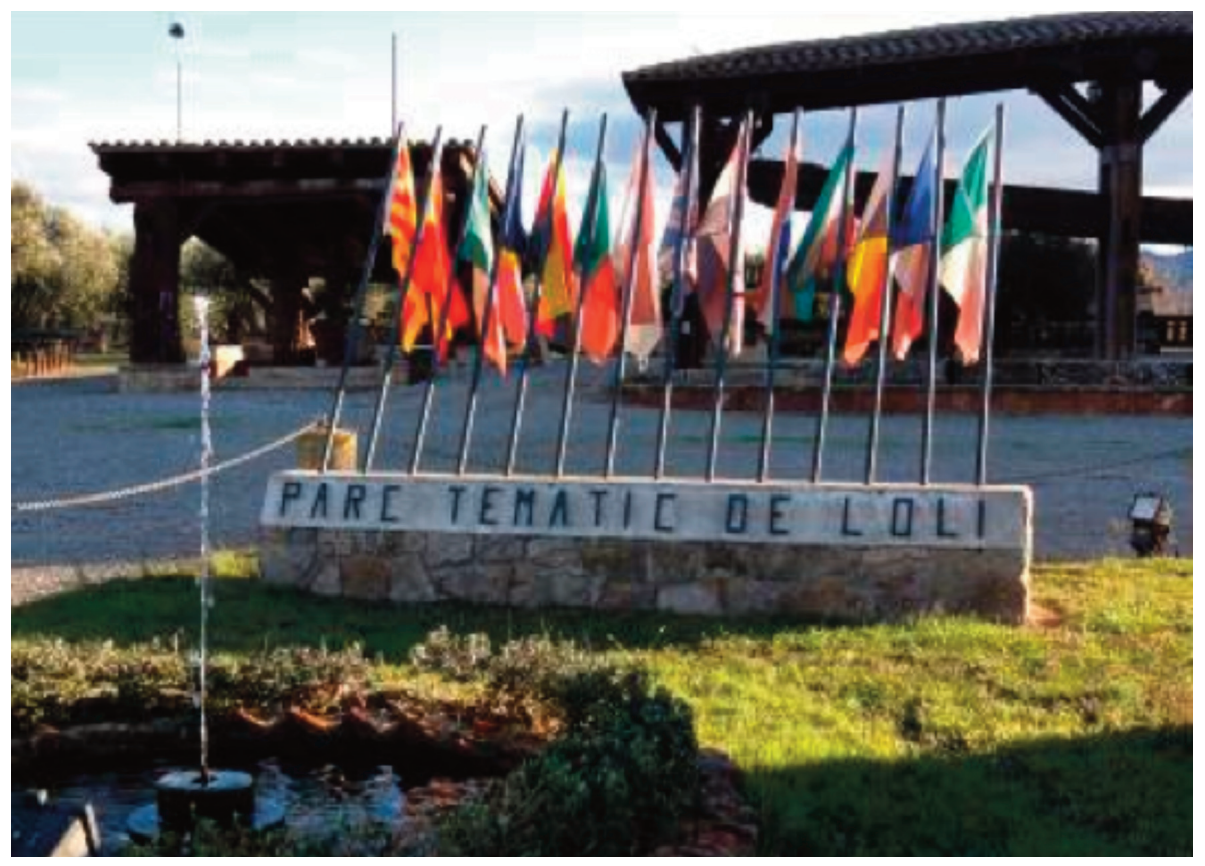

Figura 6. Entrada al Parc Temàtic de l'Oli en Borges Blanques.

Fuente: Gemma Molleví, 2014.

En 2015 se conmemoraron los 25 años de la Ruta del Cister (Generalitat de Catalunya, 2016) y se puso a la disposición de los investigadores un manual con datos estadísticos sobre la evolución, el impacto y el gran valor de esta ruta en el turismo, senderismo y desarrollo económico de las tres comarcas, así como de la inversión realizada en la última década, datos a partir de los cuales se ha elaborado la Tabla 1. Desde el año 1989 han visitado los monasterios reales más de 6 millones y medio de personas, empezando en 1989 con 268.967 personas, un pico máximo en 1994 con 343.524, un segundo pico importante en el 2000 con 317.053 y finalmente, con 199.799 en el año 2013. La evolución es bastante estable, aunque la dinámica sea en descenso desde el 2005, aunque puede ser debida a la crisis económica.

Asimismo, otro factor importante a valorar es las actividades relacionadas con el turismo que se han desarrollado durante estos 25 años y que han aumentado en número e importancia. Tal y como se puede observar en la tabla 1, en 1989 había 5 oficinas de turismo, 40 establecimientos hoteleros, 54 empresas de restauración y 18 museos y espacios de visita; en 2014, había 13 oficinas de turismo, 208 establecimientos hoteleros, 292 empresas de restauración y 70 museos y espacios de visita, además de 26 empresas de turismo activo. 
Tabla 1. Evolución de las características de la Ruta del Cister, 1989-2014

\begin{tabular}{|c|c|c|}
\hline & 1989 & 2014 \\
\hline Oficinas de Turismo & 5 & 13 \\
\hline Alojamientos & 40 & 208 \\
\hline Restauración & 54 & 292 \\
\hline Empresas de Turismo Activo & 0 & 26 \\
\hline Museos y espacios visitables & 18 & 70 \\
\hline Logotipo & $\begin{array}{l}\text { POB BLET } \\
\text { STES. CREUS } \\
\text { VALLBONANA } \\
\text { DELES MONGES }\end{array}$ & $\begin{array}{l}\text { LA RUTA } \\
\text { DEL Camp Conca de Barbera - Urgell } \\
\text { Alt CR }\end{array}$ \\
\hline Número de visitantes & 268.967 & 199.799 (año 2013) \\
\hline
\end{tabular}

Fuente: Generalitat de Catalunya, 2016.

Se ha de destacar también el cambio de logotipo de la Ruta del Cister, pues en el del año 1989 destacaba especialmente el nombre de los tres monasterios, mientras que en el actual de 2014 destacan las tres comarcas catalanas en las que se ubican cada uno de los tres monasterios y que dibujan un triángulo sobre el territorio al observarse en un mapa; por lo tanto, se hace notorio el inciso en el territorio, más que en el patrimonio, pues ese englobaría tanto aspectos patrimoniales y religiosos, como sociales y culturales.

Para las tres comarcas, estos indicadores confirman que la Ruta del Cister ha permitido dinamizar el territorio, potenciar el turismo y fomentar el desarrollo económico interior y de montaña. El estudio mencionado anteriormente también hacía hincapié en la existencia de la ruta de senderismo de gran recorrido GR175 por la Federación de Entidades Excursionistas de Cataluña, la FEDME y la Era (European Ramblers Association). Una ruta que une los tres monasterios y que ha permitido a los excursionistas conocer las tres comarcas (Generalitat de Catalunya, 2016), pudiendo ser contabilizados desde 2008 gracias a la instalación de eco-contadores: 54.536 personas han transitado desde 2008 por el GR175 La Ruta del Cister. En 2008 fueron 1.290 excursionistas en BTT y 4.755 a pie; en 2013, fueron 2.633 en BTT y 7.234 a pie. En este caso, la tendencia evolutiva es positiva tanto en BTT como a pie. 
Un elemento importante que cabe destacar son las actividades que se llevaran a cabo durante la conmemoración de los 25 años de la Ruta del Cister, como son actuaciones individuales, pero conectadas entre sí, en cada uno de los tres monasterios para destacar su monumentalidad, exclusividad y patrimonio, actividades educativas y culturales para ampliar los conocimientos de sus visitantes y la mejora turística con el impulso de la agrupación en paquetes turísticos de actividades turísticas de las tres comarcas vinculándolo con otros recursos y productos turísticos de las tres comarcas de interior y de montaña.

Esta actuación conmemorativa de la administración pública comportó el aumento en el número de visitas durante el año 2015 (Consell Comarcal de l'Urgell, 2016), tanto en los monasterios como en los otros establecimientos y actividades turísticos. Las visitas a los monasterios han aumentado un 4\%, llegando a los 185.149 visitantes (Poblet con más de la mitad, seguido en importancia por Santes Creus; Vallbona de les Monges ha sido el menos visitado, quizás por su ubicación geográfica singular). También hubo aumento de consultas tanto a las Oficinas de Turismo como a la página web de la Ruta. Se ha de destacar la venta de 2.727 entradas conjuntas, no solo para acceder a los tres monasterios sino también para beneficiarse de otras actividades y visitas a otros espacios museísticos de las tres comarcas. Espacios que han recibido un mayor número de visitas durante este 2015 fueron: Bodega Vinícola de Nulles con 5.500 visitantes, las Cuevas de la Espluga de Francolí con 46.364 visitas y el Museo del Vino de la misma localidad con 2.893 visitas, así como el Museo del Turrón y el Chocolate de Agramunt con 26.446 visitantes, entre otras, destacando la visita por los cascos monumentales de las localidades antes mencionadas de Valls o Montblanc.

\section{Conclusiones}

Los distintos casos de rutas presentados abarcan en gran parte las comarcas de interior y de montaña de Cataluña y representan una forma diversa de dinamización de la actividad turística. En primer lugar, permiten degustar el patrimonio gastronómico y enológico de un lugar en concreto, de gran variedad y riqueza. Además, permiten dar a conocer todo un conjunto de recursos culturales y naturales, que al estar enmarcados en el contexto de una ruta tienen una mayor visibilidad. Esta visibilidad tiene una retroalimentación mutua. En consecuencia, las rutas son una oportunidad para incrementar la actividad turística ya que, en territorios de interior y de montaña, al mismo tiempo que alguien se interesa por el senderismo, el esquí o el rafting, se puede degustar la gastronomía o conocer el patrimonio cultural, lo cual permite ampliar los conocimientos y experiencias auténticas.

En segundo lugar, estas rutas permiten reducir la estacionalidad turística tan presente en otras tipologías turísticas como la de sol y playa o de la nieve. Se trata, como ya se ha visto antes, de rutas que se pueden realizar a lo largo de todo el año, permitiendo 
estancias de diferente duración, así como incluso la fragmentación de la ruta en diferentes tramos y visitas.

En tercer lugar, las rutas gastronómicas y enológicas dan nuevas perspectivas económicas al sector hotelero y de la restauración de las comarcas catalanas de interior y de montaña y permiten a los grupos de campesinos y ganaderos la obtención de ingresos extras, al mismo tiempo que se abren oportunidades laborales para los jóvenes de estas comarcas. Es el caso especialmente de EnoturismePenedès y la Ruta del Cister, las dos rutas más conocidas y con más recorrido de las mencionadas. Estas sinergias, en particular relacionadas con los establecimientos de restauración, también se han observado para el caso de la Ruta Artesana.

En relación con el alcance geográfico de las cuatro rutas presentadas, se desprende que las mismas engloban gran parte del territorio catalán, pues Cataluña es un destino de gran diversidad territorial, delimitada por un lado por el Mar Mediterráneo, y por el otro por la cordillera de los Pirineos. La geografía es de mayor interés si cabe en el caso de la ruta EnoturismePenedès, donde hay que tener en cuenta que se desarrolla en un valle ubicado entre dos sierras, una litoral y otra prelitoral. También es importante el hecho que si bien entre las rutas analizadas no hay superposición, hay otras rutas gastronómicas donde esto sí que sucede. Un ejemplo son las rutas de la Miel y del Aceite, que se desarrollan en territorios que a la vez se encuentran dentro de otra ruta ubicada en un territorio más extenso como es la Ruta del Vino de Lleida-Costers de Segre. Esto representa una gran oportunidad, no solo desde un punto de vista promocional sino también para demostrar que las rutas gastronómicas pueden ser complementarias, y beneficiar ampliamente el desarrollo de una región en particular, y no únicamente los municipios concretos que una ruta comprende.

Una manera de incentivar el turismo, tanto en cuanto a su demanda interior como exterior es dar a conocer el territorio más cercano y propio, el de nuestros antepasados, su forma de vivir y de disfrutar la vida y su manera de trabajar y producir unos alimentos que luego se degustan en la mesa.

La gastronomía nace de las actividades del sector primario, y los productos artesanos tienen cada vez una mayor aceptación. Esto es debido a su estrecha relación con los métodos de producción sostenibles, y también ligado a una cadena de distribución directa entre el productor y el visitante. Se trata, como en el caso del vino y el queso, de productos tradicionales y naturales que a su vez tienen unos significados históricos y culturales muy arraigados.

Este artículo muestra mayoritariamente rutas alrededor de productos con Denominación de Origen Protegida, y por lo tanto su potencial como recurso turístico es evidente. Las etiquetas de calidad como las DOP dan un valor añadido a los productos, y también en el contexto español son muchos y variados los casos de rutas alrededor de 
los mismos. No obstante, no son las rutas un patrimonio exclusivo de los productos con DOP. Es importante también decir que hay ejemplos además de las rutas que, como por ejemplo las ferias, son cabales para diversificar la oferta y generar un factor de atracción para la demanda. Otro elemento a considerar en el marco de la oferta del turismo gastronómico es la vinculación entre productos, y para el caso del queso y el vino hay ejemplos consolidados tanto en productos -Queso de Murcia al Vino- como en eventos -la Feria del Queso y el Vino de Avilés-. Todo esto aún tiene más importancia en los contextos catalán y español ya que la gastronomía tiene un hecho diferencial como es el de formar parte de la dieta mediterránea, que fue declarada Patrimonio de la Humanidad por la Unesco en el año 2010. Tal como se ha podido valorar con los datos turísticos, en especial los de la Ruta del Cister y EnoturismePenedès por su mayor trayectoria, este tipo de turismo aumenta con los años. Cabe recordar que EnoturismePenedès (creada a principios de siglo) disponía de cerca de medio millón de turistas, mientras que la Ruta del Cister (creada en 1989) estaba en los 200.000 y la Ruta Lleida-Costers del Segre (creada en 2010) fue visitada por unos 36.000 turistas. La Ruta Artesana es de reciente creación, por lo que todavía no se disponen de datos; su inclusión en este trabajo radica en su singularidad, pues es un turismo de interior y de montaña muy concreto, centrado principalmente en el queso. Tanto ACEVIN como los organizadores y administradores de estas rutas están interesados en potenciar este tipo de turismo porque permite dar a conocer el territorio, ofrecer diferentes tipos de turismo, descongestionar los destinos turísticos más conocidos y masificados y, sobre todo, porque son un motor de desarrollo para las regiones del interior y ofrecen una complementariedad a la economía de esas áreas rurales y ayudan a la protección del paisaje, natural y humano.

Si bien este artículo presenta como limitación el hecho de ser descriptivo en esencia, y es más cualitativo que cuantitativo, puede servir de base para futuras investigaciones que analicen el impacto económico derivado de las rutas turísticas y gastronómicas. A la vez, las rutas analizadas son solo una muestra de integración de los productos locales del vino y el queso en un producto turístico, y por lo tanto hay muchas otras rutas en el contexto del territorio de Cataluña sujetas a ser estudiadas. Las futuras oportunidades de investigación deberían ir también encaminadas a mostrar la diversidad de las rutas, la complementariedad entre los distintos productos y servicios turísticos, y demostrar empíricamente su capacidad para el desarrollo económico en comarcas de interior y de montaña así como su potencial para dar a conocer los territorios y sus gentes.

\section{Bibliografía}

Acevin, 2015. Informe de visitantes a bodegas y a museos del vino asociados a las Rutas del Vino de España. Año 2014. Disponible en http://www.wineroutesofspain.com/bd/archivos/archivo441.pdf (Consulta: 20.07.2016).

Bèssière, J., 1998. Local development and heritage: traditional food and cuisine as tourist attractions in rural areas. Sociologia Ruralis, 38(1), pp. 21-34. 
Bèssière, J., 2006. Manger ailleurs, manger local. Revue Espaces, 242, pp. 16-21.

Briedenhann, J. y Wickens, E., 2003. Tourism routes as a tool for the economic development of rural areas - vibrant hope or impossible dream?. Tourism Management, 25, pp. 71-79.

Cànoves, G. [Dir], 2004. El turisme rural a Catalunya: una aposta mediambiental i de qualitat. Barcelona: UAB i Fundació Abertis. Disponible en http://seneca.uab.es/ter/Turismerural.pdf (Consulta: 14.03.2015).

Cànoves, G., Herrera, L. y Cuesta, L., 2005. Turismo rural en Cataluña: condicionantes de la oferta y la demanda. Investigaciones Geográficas, 37, pp. 5-26.

Cànoves, G., Herrera, L. y Villarino, M., 2005. Turismo rural en España: paisajes y usuarios, nuevos usos y nuevas visiones". Cuadernos de Turismo, 15, pp. 63-76.

Consell Comarcal de l'Urgell, 2016. Augmenten els visitants de la Ruta del Cister durant l'any 2015. Disponible en http://urgell.cat/blog/2016/01/27/augmenten-els-visitants-de-la-ruta-del-cister-durant-lany-2015/ (Consulta: 20.07.2016).

Díaz, I. y Llurdés, J.C., 2013. Reflexiones sobre el turismo de proximidad como una estrategia para el desarrollo local. Cuadernos de Turismo, 32, pp. 65-88.

Enoturisme Penedès, 2016. enoturismePenedès. Disponible en http://www.enoturismepenedes. cat/es (Consulta: 20.06.2016).

Fusté Forné, F., 2014. Simbiosis entre agroramaderia i turisme: la indústria formatgera a la comarca del Pallars Sobirà. En: Boyra, J., Fusté, F. y Molleví, G., Creació i comercialització de productes turístics. Barcelona: EU Formatic Barcelona, pp. 125-133.

Fusté Forné, F., 2015a. El turisme gastronòmic: autenticitat i desenvolupament local en zones rurals. Documents d'Anàlisi Geogràfica, 61 (2), pp. 289-304.

Fusté Forné, F., 2015b. Cheese tourism in a World Heritage site: Vall de Boí (Catalan Pyrenees). European Journal of Tourism Research, 11, pp. 87-101.

Fusté Forné, F., 2016. El queso como recurso turístico para el desarrollo regional: la Vall de Boí como caso de estudio. PASOS Revista de Turismo y Patrimonio Cultural, 14(1), pp. 243-251.

Generalitat de Catalunya, 2014. Commemoració dels 25 anys de la creació de la Ruta del Cister. Disponible en http://premsa.gencat.cat/pres_fsvp/docs/2014/12/12/13/50/bccaacd1-0f354c23-98dc-78da7b0a2f5e.pdf (Consulta: 20.07.2016).

Generalitat de Catalunya, 2015. Taula 11. Col·leccions obertes al públic. Visites 2014. Disponible en http://cultura.gencat.cat/web/.content/dgpc/museus/area_de_difusio_i_explotacio/estadistiques_de_col_leccions/2014/11.2014.Visites-per-ordre-de-nom-de-municipi.pdf (Consulta: 20.07.2016).

Getz, D. y Brown, G., 2006. Critical success factors for wine tourism regions: a demand analysis. Tourism Management, 27(1), pp. 146-158.

Guerra, I.R., Moreno, V.M. y López, V.M.M., 2014. El oleoturismo como atractivo turístico en el medio rural español. Papers de Turisme, 49-50, pp. 89-103.

Hall, C.M., Sharples, L., Cambourne, B. y Macionis, N., 2009. Wine tourism around the world. Routledge. 
Hernández Ramírez, J., 2011. Los caminos del patrimonio. Rutas turísticas e itinerarios culturales. PASOS Revista de Turismo y Patrimonio Cultural, 9(2), pp. 225-236.

Incavi, 2015. Institut Català de la Vinya i el Vi. Disponible en www.incavi.cat (Consulta: 23.03.2015).

Lignon-Darmaillac, S., 2009. L'oenotourisme en France. Nouvelle valorisation des vignobles. Analyse et bilan. Bordeaux: Éditions Féret.

López-Guzmán, T., García, J.R. y Rodríguez, Á.V., 2013. Revisión de la literatura científica sobre enoturismo en España. Cuadernos de Turismo, 32, pp. 171-188.

López-Guzmán, T. y Margarida, M., 2011. Turismo, cultura y gastronomía. Una aproximación a las rutas culinarias. En International Conference on Tourism and Management Studies. Algarve, pp. 915-922.

MAGRAmA, Ministerio de Agricultura, Alimentación y Medio Ambiente, 2015. Denominaciones de Origen e Indicaciones Geográficas Protegidas. Disponible en http://www.magrama.gob.es/ es/alimentacion/temas/calidad-agroalimentaria/calidad-diferenciada/dop/default.aspx (Consulta: 22.03.2015).

Medina, F.X. y Tresserras, J., 2008. Turismo enológico y rutas del vino en Cataluña. Análisis de casos: DO Penedès, DO Priorat y DO Montsant. PASOS Revista de Turismo y Patrimonio Cultural, 3(6), pp. 493-509.

Millán Vázquez de la Torre, M.G., Morales Fernández, E.J. y Agudo Gutiérrez, E.M., 2010. El oleoturismo como motor de desarrollo rural: La denominación de origen de montoro-adamuz. Mundo Agrario, 11 (21).

Molleví Bortoló, G., 2008. La cultura del vino en Cataluña. Barcelona: Editorial Davinci Continental.

Molleví Bortoló, G., 2014. Enoturisme de la DO Costers del Segre: el cas dels cellers pirinencs". En: Boyra, J., Fusté, F. y Molleví, G., Creació i comercialització de productes turístics. Barcelona: EU Formatic Barcelona, pp. 221-234.

Molleví Bortoló, G., 2015. "El enoturismo en España", XXXVI Jornadas de Viticultura y Enologia de Tierra de Barros, Almendralejo, Centro Universitario Cultural Santa Ana, pp. 333-351.

Molleví Bortoló, G., 2016. "El enoturismo en Catalunya", XXXVII Jornadas de Viticultura y Enología de Tierra de Barros, Almendralejo, Cultural Santa Ana Centro Universitario, pp. 155-176.

Oliver, J.M., Gual, V., Gonzalvo, G., Prats, J., Baluja, J., Carreras, A., Sans, J.M., Duch, J., Rovira, J. y Borrell, J., 2008. Cister. Monestirs Reials a la Catalunya Nova. Valls: Cossetània Edicions.

Turisme de la Seu d'Urgell, 2015. Fet a mà. Disponible en http://www.turismeseu.com/que-fer/ gastronomia/fet-a-ma (Consulta: 04.04.2015).

Vinseum, 2015. Historia. Disponible en http://www.vinseum.cat/?cas/Vinseum/Historia (Consulta: 30.03.2015).

Visa, E., Febrero 2015. Aprovechamiento del patrimonio paisajístico. El turismo en rosa. Aitona sigue la estela de Japón y el Valle del Jerte y programa visitas a los frutales en floración. Disponible en http://www.elperiodico.com/es/noticias/sociedad/aitona-programa-visitas-losfrutales-floracion-4038066 (Consulta: 14.03.2015).

VV.AA., 2008. Los cistercienses. (In situ). Vic-en-Bigorre (Francia): MSM.

Yin, R., 1994. Case Study Research: Design and Methods. Thousand Oaks, CA: SAGE. 
